\title{
Climatology-aware health management information system to enhance cholera epidemic analysis and prediction in Tanzania
}

\author{
Judith Leo $^{1^{*}}$, Edith Luhanga ${ }^{2}$ and Kisangiri Michael ${ }^{3}$ \\ Ph.D. Scholar, School of Computation and Communication Science and Engineering, Nelson Mandela African \\ Institution of Science and Technology, P.O.Box 447, Arusha, Tanzania ${ }^{1}$ \\ Lecturer, School of Computation and Communication Science and Engineering, Nelson Mandela African Institution \\ of Science and Technology, P.O.Box 447, Arusha, Tanzania ${ }^{2}$ \\ Senior Lecturer, School of Computation and Communication Science and Engineering, Nelson Mandela African \\ Institution of Science and Technology, P.O.Box 447, Arusha, Tanzania ${ }^{3}$
}

Received: 09-May-2019; Revised: 24-June-2019; Accepted: 26-June-2019

(C)2019 Judith Leo et al. This is an open access article distributed under the Creative Commons Attribution (CC BY) License, which permits unrestricted use, distribution, and reproduction in any medium, provided the original work is properly cited.

\begin{abstract}
The cholera epidemic remains a public health threat in many developing countries including Tanzania. It affects vulnerable populations living with an unreliable water supply and sub-standard sanitary conditions. Various studies have found that the occurrence of cholera has strong linkage with environmental factors such as climatology aspects and geographical location. In addition, climatology has been strongly linked to the creation of weather patterns that favor the transmission and growth of Vibrio cholerae, which causes the disease. There are several studies that have been conducted to integrate environmental factors into the existing health management information systems (HMISs) in order to enhance the analysis of cholera epidemics in Tanzania. This work explored how well climatology factors have been integrated into these existing HMISs and the potential of the systems in enhancing cholera epidemics analysis. We found that most of the existing HMISs have not explicitly integrated environmental and climatology features for effective analysis of diseases. We thus proposed the design and development of an effective Climatology-aware HMIS. Then, evaluate it with clinical and environmental data such as; geographical location, weather, conditions of the day, and date on set, of 22 medical students staying in the Mweka district in Tanzania. The results of system evaluation showed that $87 \%$ provided positive feedback on the capacity of the developed system, towards enhancing the cholera epidemic analysis and prediction linked with environmental factors particularly the climate change variables. The study recommends the review of systems and policies in the health sectors in order to adapt climatology factors.
\end{abstract}

\section{Keywords}

Health management information systems, Cholera epidemics, Climatology, Environmental factors.

\section{Introduction}

1.1Background introduction

Cholera is an acute intestinal infectious disease caused by Vibrio cholerae (V. cholerae) [1]. It is an important public health problem worldwide [2]. The dynamics of cholera in most developing countries are related to several interactions between human beings, pathophysiological, and environmental [3, 4]. These environmental factors include geographical location and climatology factors. Climatology factors are climate variables such as temperature, rainfall, humidity, and wind.

\footnotetext{
*Author for correspondence
}

Environmental and climatological factors affect cholera due to the facts that, V. cholerae are strongly controlled by water temperature, salinity, and the presence of copepods which in return, are controlled by climate variability [5] and seasonal dynamics of weather changes [6]. In order to counteract the climate water-borne epidemics, there have been a number of studies and reviews over the past fifty years on health and environmental related problems and policies on climate adaptation in Tanzania [7]. However, up to date, there is no single policy in the country addressing climate change impact on waterborne epidemics. Most initiatives and efforts have focused on providing medical interventions in response to the cholera outbreaks and much less attention has been directed towards investing in the 
development of proper mechanisms for effective analysis of the disease. The World Health Organization (WHO) also reports that cholera epidemics with linkages to environmental factors are not well established [8]. They further emphasize that "it is important for recognition of environmental factors from Environmental Management Information Systems (EMISs), in order to effectively identify probable clinical case location trends, its seasonality, transmission range, epidemic size, and predictability" [9].

EMIS is a tool for systematically obtaining, processing, and making relevant environmental information available. EMIS has been the great driving force in the collection of the required environmental data for disease analysis. However, most of the existing EMISs are not designed for timely and effective support HMISs activities such as analysis, treatment, and prediction of cholera epidemics [10]. The objective of this work was (i) to determine the extent to which HMISs that are prevalent in the Tanzanian health-sector have been integrated with EMISs. We found that integration was low with only geo-locations being made available to HMIS. (ii) We therefore proposed, developed and evaluated a climatology-aware HMIS through a field study with 22 participants consisting of 10 males and 12 females, with an average age of 30 years old, and a specialty ratio of $60 \%$ from waterborne epidemics, $30 \%$ of the e-Health systems and $10 \%$ from medical administration. We found that user acceptance of the proposed system was very high at an average rate of $87 \%$ and that the system enabled participants to effectively submit essential health and environmental data, and also, analyze their results using map-based reports and excel formats.

\subsection{Literature review}

The following subsections present an overview of studies on various cholera initiatives, HMISs, and EMISs in Tanzania and other countries.

1.2.1 Studies highlighting essential factors for cholera analysis

There are several studies that have highlighted the essential factors required for cholera analysis. These studies include the study by Torres Codeco CT [11], who modeled transmission of cholera using basic Susceptible Infected and Recovered (SIR) approach coupled with an aquatic reservoir of $V$. cholerae. The other studies were done by $[3,12-15]$ on environmental signatures associated with cholera epidemics. Other studies which focused on Tanzania include [6, 16-18]. Their findings on essential factors are similar to those of the previously presented studies. Overall, these studies found that ocean waters along with zooplankton community, climate, geo-location, season (date and time), human behavior, and salinity are important factors in the ecology of $V$. cholerae and useful predictors of cholera epidemics. Furthermore, these studies bring some new insights into cholera epidemiology on essentially quantifying collection of into one platform.

1.2.2 Non-ICT-based initiatives to end cholera in Tanzania

In Tanzania, a number of programs to counteract the impact of environmental factors in the transmission of cholera epidemics have been initiated. Such initiatives include the one health approach which aims at expanding interdisciplinary collaborations and communications in all aspects of health care for humans, animals, and the environment [19]. Another initiative is Tanzania's One Health Strategic Plan of 2015-2020 which focuses on five thematic areas, namely [20]: (i) training, advocacy, and communication (ii) preparedness and response (iii) research (iv) disease surveillance, prevention and control, and (v) coordination. Other initiatives include improved water, sanitation, and hygiene (WASH) [21, 22], WHO road map to reach 2030 targets [23], Sustainable Development Goals (SDGs) [24] and WHO country cooperation strategy 20102015 (Yesserie 2015). In brief, all of these initiatives can be categorized into: -

(i) Early detection and quick response to contain cholera outbreaks: These interventions aim at controlling the outbreaks wherever they may occur through early detection and rapid response mechanisms such as robust community engagement, strengthening early warning surveillance and laboratory capacities, and supply readiness [25].

(ii) A targeted multi-sectoral approach to prevent cholera recurrence: The multi-sectoral approach uses a combination of health, finance, and environment sectors to prevent recurrence of cholera on relatively small areas most heavily affected by cholera [26].

(iii) An effective mechanism of coordination for technical support, advocacy, resource mobilization, and partnership at local and global levels. This is done by organizations including global task force on cholera control (GTFCC) which are positioned to bring improved WASH through the use of oral cholera vaccines and offer an effective country-driven 
Judith Leo et al.

platform to support advocacy and communications, fundraising, inter-sectoral coordination, and technical assistance [27].

1.2.3 ICT-based initiatives to end cholera epidemics In Tanzania, as in most developing countries, there has been a growing effort to strengthen the HMISs in use and implementing of early warning surveillance mechanisms [28]. This effort has been mostly concentrated on specific initiatives and programs such as revision of data collection tools for expanded programs of immunization, reproductive and child health services, disease monitoring, analysis, prediction, and evaluation for sexually transmitted and neglected tropical diseases such as HIV-AIDS, malaria, and cholera [29]. A review of existing systems such as; OpenMRS, Care2X [30] and EMIS Land Management for healthcare was conducted by [31-35]. Other systems which were reviewed include an integrated global positioning system (GPS) and geographical information system (GIS) which maps cholera cases using satellite-based recording systems in order to investigate the outbreak [14]. This system potentially acts as an early warning system for cholera in many developing countries, especially during the start of an outbreak. The other system is MAX software which was used for qualitative data analysis during Kenya's national cholera outbreak of 2015 and the authors described the challenges affecting cholera preparedness of 44 health facilities [36]. Cholera mathematical models which assist in the prediction and analysis of diseases have also been reviewed e.g. example, the model developed by Trærup et al. which has integrated historical data on temperature and rainfall with the burden of disease from cholera in Tanzania, and uses social economic data to control the impacts of general development on the risk of cholera [5]. Table 1 summarizes the features found in each system that was reviewed in this study.

Table 1 Summarizes features found in each system that was reviewed in this study

\begin{tabular}{|c|c|c|c|c|c|c|c|c|}
\hline Features & $\begin{array}{c}\text { Study1 } \\
{[31]} \\
\end{array}$ & $\begin{array}{c}\text { Study } 2 \\
{[32]} \\
\end{array}$ & $\begin{array}{c}\text { Study } 3 \\
{[37]}\end{array}$ & $\begin{array}{c}\text { Study } 4 \\
{[34]}\end{array}$ & $\begin{array}{c}\text { Study } 5 \\
{[35]}\end{array}$ & $\begin{array}{c}\text { Study } 6 \\
{[14]}\end{array}$ & $\begin{array}{c}\text { Study } 7 \\
{[36]} \\
\end{array}$ & $\begin{array}{c}\text { Study } 8 \\
{[5]}\end{array}$ \\
\hline Study area & Tanzania & Tanzania & Tanzania & Tanzania & $\begin{array}{l}\text { United } \\
\text { States }\end{array}$ & India & Kenya & Tanzania \\
\hline $\begin{array}{l}\text { Patient full- } \\
\text { name }\end{array}$ & $\sqrt{ }$ & $x$ & $\sqrt{ }$ & $\sqrt{ }$ & $\sqrt{ }$ & $\sqrt{ }$ & $\sqrt{ }$ & $\sqrt{ }$ \\
\hline $\begin{array}{l}\text { Patient } \\
\text { historical } \\
\text { details }\end{array}$ & $\sqrt{ }$ & $x$ & $\sqrt{ }$ & $\sqrt{ }$ & $\sqrt{ }$ & $\sqrt{ }$ & $\sqrt{ }$ & $\sqrt{ }$ \\
\hline $\begin{array}{l}\text { GIS-based } \\
\text { geographical } \\
\text { Home } \\
\text { Address }\end{array}$ & $x$ & $\sqrt{ }$ & $x$ & $\sqrt{ }$ & $\sqrt{ }$ & $\sqrt{ }$ & $\sqrt{ }$ & $\sqrt{ }$ \\
\hline Date on set & $\sqrt{ }$ & & $\sqrt{ }$ & $\sqrt{ }$ & $\sqrt{ }$ & $\sqrt{ }$ & $\sqrt{ }$ & $\sqrt{ }$ \\
\hline Time on set & $x$ & & $x$ & $\sqrt{ }$ & $\sqrt{ }$ & $x$ & $x$ & $x$ \\
\hline Rainfall & $x$ & & $x$ & $x$ & $x$ & $x$ & $x$ & $\sqrt{ }$ \\
\hline Temperature & $x$ & & $x$ & $x$ & $x$ & $x$ & $x$ & $\sqrt{ }$ \\
\hline Humidity & $x$ & & $x$ & $x$ & $x$ & $x$ & $x$ & $x$ \\
\hline Wind & $x$ & & $x$ & $x$ & $x$ & $x$ & $x$ & $x$ \\
\hline $\begin{array}{l}\text { Geographical } \\
\text { features of } \\
\text { an area such } \\
\text { as rivers, } \\
\text { dams, } \\
\text { oceans, etc. }\end{array}$ & $x$ & & $x$ & $\sqrt{ }$ & $\sqrt{ }$ & $\sqrt{ }$ & $\sqrt{ }$ & $x$ \\
\hline
\end{tabular}

WHO monitoring and evaluation report (Security and Cluster 2016) and the studies presented in this literature review show that initiatives for ending cholera epidemics have improved in terms of creating WASH programs and robust community engagements. However, most of the countries affected by cholera have (i) fragmented health and 164 environmental initiatives and systems, (ii) lack of shared data standards, (iii) lack of effective tools for timely data analysis and early warnings, (iv) no climatology impact captured in the cholera epidemics, (v) no quality data, (vi) no information flows which address the local levels, such as district and ward offices, (vii) poor and inadequate resources 
and infrastructures for healthcare activities, and lastly, (viii) lack of clear understanding of the purpose of data collection [38-40]. This fact is clearly demonstrated by seasonal occurrence and reoccurrence of cholera epidemics with the same causes and transmission patterns in Tanzania [6]. In addition, in Tanzania less than $50 \%$ of hospitals use HMISs and up until 2015, the HMISs in use collected required environmental data from the ICT-based meteorological agency in order to analyze cholera outbreaks in an area [17, 40] This delays timely analysis of the disease [28-31]. ICTs such as Geographical Information System (GIS), machine learning (ML), mobile applications, sensors, and satellites, if properly utilized, have enormous potential towards improving the processes of timely data collection, data presentation, and dissemination of evidence-based analysis [41].

GIS in recent years has emerged as a group of innovative components, useful for early problem detection, solving and ascribing priorities in the environment of limited resources like Tanzania [42-44]. From a community health perspective, GIS can potentially act as powerful, evidence-based practice tools for timely and detailed collection of geographical area [43]. In addition, the phones and their application appear particularly well-suited to work in health education, healthcare data security, disease prevention, and treatment, tracking of environmental factors. In addition, mobile applications can potentially be used to overcome some of the traditional barriers in Tanzania and other African countries towards accessing essential information and services, such as geographic location, integration with other systems, gender, and social stigma [45]. Furthermore, satellites and sensors are the emerging ICTs which play a great role in the timely collection of environmental data, remote sensing, communication, and navigation. They also, provide valuable information on changing environmental conditions and weather patterns which can assist in early detection and timely response to disease outbreaks. Good enough, nowadays, satellite and sensor technologies run on a Smartphone [46]. The Smartphone has greatly encouraged application development and has proven to be effective [47]. Moreover, ML, Smartphone and advanced 3G wireless networking have shown a gradual increase in the number of users, especially in developing countries, including Tanzania [48] as presented in Figure 1. This paper, therefore, determines to what extent GIS and other technologies have been integrated with HMIS, and how much they are used, to allow much timely collection of environmental data. The rest of this paper includes; section 2 which covers the applied methods, section 3 which present the results, and lastly section 4 which concludes with a brief discussion.
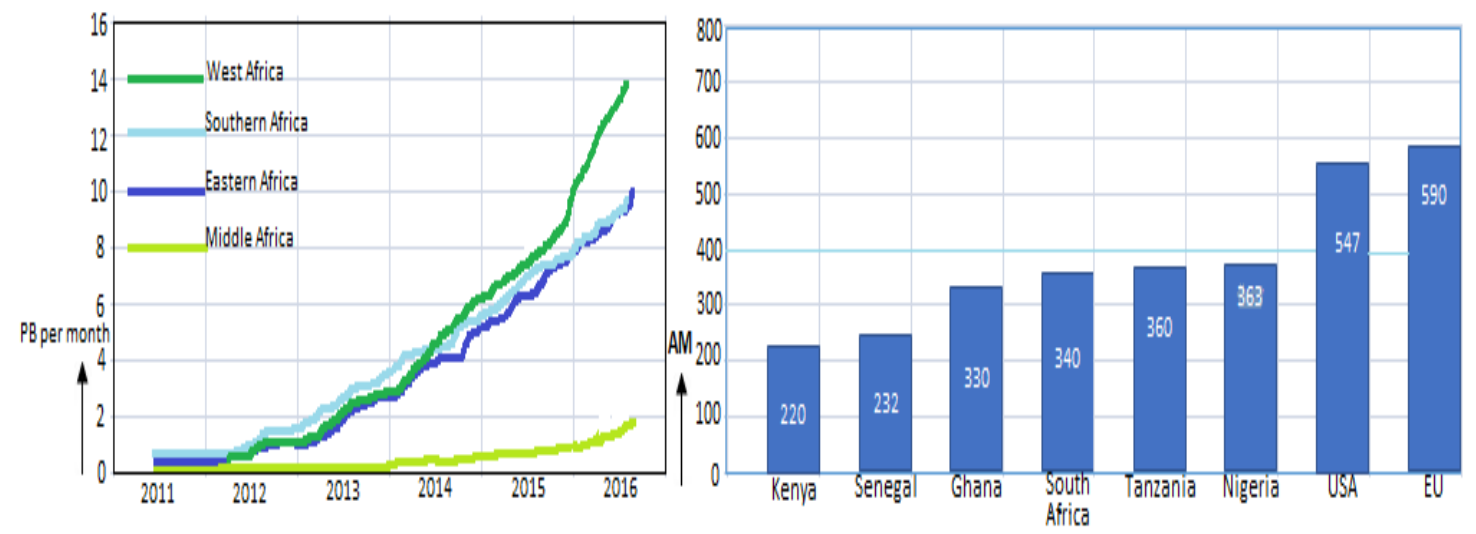

Figure 1 Estimated total mobile internet traffic (PB) in SSA, by sub-region (2011-2016); and assigned mobile spectrum (AM) for leading SSA countries, $2011(\mathrm{MHz})$ by Wireless Intelligence and Deloitte analysis [48]

\section{Methods}

The study followed the design science research methodology (DSRM) which consists of three stages: (i) problem identification (ii) solution design and (iii) evaluation and validation. We chose DSRM because it is outcome-based methodology, which offers guidelines for evaluation and iteration within the project. In addition, DSRM focuses on improving the functional performance of the interfaces [49]. Overall, the study took a total period of one year and three months, from January 2017 to March 2019. 


\subsection{Area of study}

The study was done in Dar Es Salaam and Kilimanjaro regions in Tanzania. This is because Tanzania is among the African countries with frequent cholera outbreaks [5] and most of the cases in Tanzania occur in the regions of Dar Es Salaam, Tanga, Morogoro, and Kilimanjaro which have limited water supply and poor sanitary conditions $[17,38]$. The cholera cases in Tanzania also fluctuate with the seasonal weather changes [16]. For example, the recent cholera epidemic which occurred between August 2015 to April 2016 with 3,371 cases and 36 deaths [17] started during the heavy rainfall season in the country. Figure 2 shows the number of cases reported and deaths in the Dar Es Salaam region during the 2015-2016 epidemics which also fell during the rainy season.

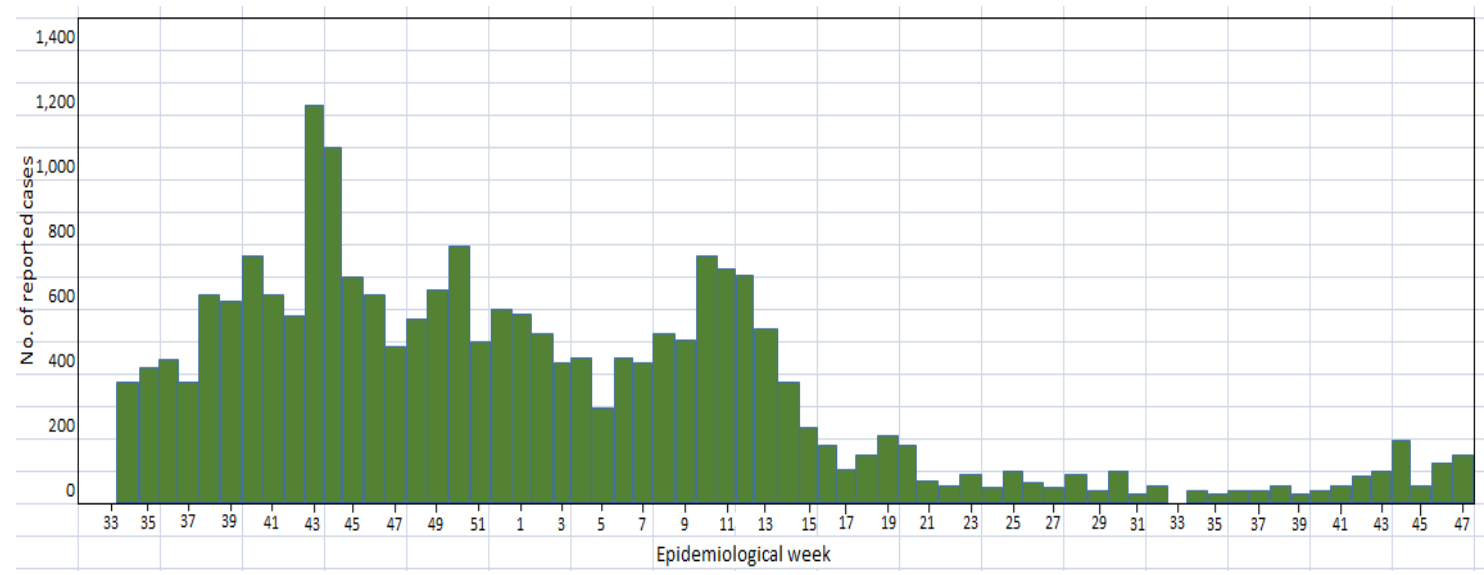

Figure 2 Number of reported cholera cases in Tanzania from 15 August 2015 to 26 November 2016 [17]

\subsection{Problem identification stage}

In the problem identification stage, we first conducted a literature review to determine which climatology aspects are known to be important for cholera epidemic analysis and prediction, and which of these have been integrated into HMIS in literature. We then aimed to determine the extent of integration and status of use of this enhanced HMIS in Tanzanian hospitals as well as perceptions of the benefits of these systems.

We conducted interviews followed by an observation session with 30 participants from Dar Es Salaam and Kilimanjaro regions. The participants consisted of 19 males and 11 females, with an average age of 32 years old, and an occupation ratio of $60 \%$ from the health sector, $30 \%$ of the ICT sector and $10 \%$ from other sectors.

During the interview session, we asked questions such as (i) how many environmental factors are included in your HMIS, (ii) how did you decide on the environmental factors to include, (iii) how do you collect and use environmental data combined with patient diagnosis data, (iv) what should be done in order to enhance cholera epidemics analysis linked with environmental factors, particularly the climatology variables, (v) Is climatology factor essential for cholera analysis and how, and (vi) What challenges do you face in the currents HMIS towards compiling reports for cholera epidemics in Tanzania, etcetera. Notes were taken during the interview and an inductive coding approach was used during the analysis. We tabulated frequency of responses in order to determine the most included features and the reason for their inclusion. We also tabulated responses on the reason for exclusion of the other.

\subsection{Solution design and development}

Rapid application development (RAD) approach was used for solution design because of the short and iterative development cycles with high-quality results of information systems [50] that it offers. A total of eight iterations were conducted. We evaluated user interface design, features, and functionality as well as the performance (speed) and security factor using high-fidelity prototypes developed with Java Server Page (JSP), JavaScript and Java codes, MySQL and JSON.

\subsection{System evaluation}

For system evaluation, a field study of three months was conducted using the final prototype. The study consisted of 22 fourth-year medical students from the Kilimanjaro Christian Medical Centre (KCMC) in the Kilimanjaro-Mweka district in Tanzania. The KCMC 
is the referral hospital for the Kilimanjaro region. The medical students consisted of 10 males and 12 females, with an average age of 30 years old, and a specialty ratio of $60 \%$ from waterborne epidemics, $30 \%$ of the e-Health systems and $10 \%$ of medical administration and the study was conducted from January to March 2019.

The questionnaires asked whether the developed system has truly enhanced the epidemic analysis of cholera with linkages to environmental factors and fulfilled the proposed system requirements. Other questions focused on determining efficiency, accessibility, security, maintainability, and interoperability levels of the developed system. Data from the questionnaires were analyzed statistically using the statistical package for social science (SPSS) [51].

\section{Results}

The section presents the results obtained towards the development of an effective Climatology-aware HMIS.

\subsection{Proposed functional and non-functional requirements}

The collected functional and non-functional requirements for the proposed system are described in Table 2.

Table 2 Proposed system requirements

\begin{tabular}{cll}
\hline \multicolumn{1}{c}{ Requirements } & \multicolumn{1}{c}{ Functional Requirements } \\
\hline SN & \multicolumn{1}{c}{$\begin{array}{l}\text { Submit health and environmental data, } \\
\text { including the climatology variables, date and } \\
\text { time on set, patient's personal, and home } \\
\text { geographical location. }\end{array}$} & $\begin{array}{l}\text { Users, Staging DB and EMIS should submit to and from, all essential data } \\
\text { automatically. }\end{array}$ \\
\hline 2. & Search records per keywords and images. & $\begin{array}{l}\text { The system should enable users to search for data using keywords and } \\
\text { images. }\end{array}$ \\
\hline 3. & Generate visual reports. & $\begin{array}{l}\text { The system should generate visual reports such as Excel and map-based } \\
\text { reports which contain patient's details, laboratory results, geographical } \\
\text { location, climatology variables, date and time on set. }\end{array}$ \\
\hline Non-functional requirements & \begin{tabular}{l} 
The system should allow only registered users to access their information. \\
\hline 1
\end{tabular} Security & $\begin{array}{l}\text { The system should do tasks required successfully without wasting time or } \\
\text { energy. }\end{array}$ \\
\hline 2 & Efficiency & $\begin{array}{l}\text { The system should be easy to use and access, and allow offline registration } \\
\text { and data submission when there is no internet connection. }\end{array}$ \\
\hline 3 & Accessibility & The maintainability should easily be done by the system administrator. \\
\hline 4 & Maintainability & The system should allow upgrading when needed. \\
\hline 5 & Interoperability &
\end{tabular}

\subsection{Result of the system design process}

Based on the obtained system requirements, we adopted a client-server model which utilizes a model view controller (MVC) domain. This is because MVC can easily design, define the structure, and enable rapid development of the proposed system. In addition, MVC facilitates code reuse and parallel development to enable modification of other parts of the system without affecting the entire system [52] as shown in Figure 3. In Figure 3, the CLIENT module describes users of the system such as patients and system administrator. Then, the client (users) uses the VIEW module to send and receive the required information to and from the server. In return, the CONTROLLER module controls information flow from users to the staging DB, EMIS and the HMIS, and vice versa. 


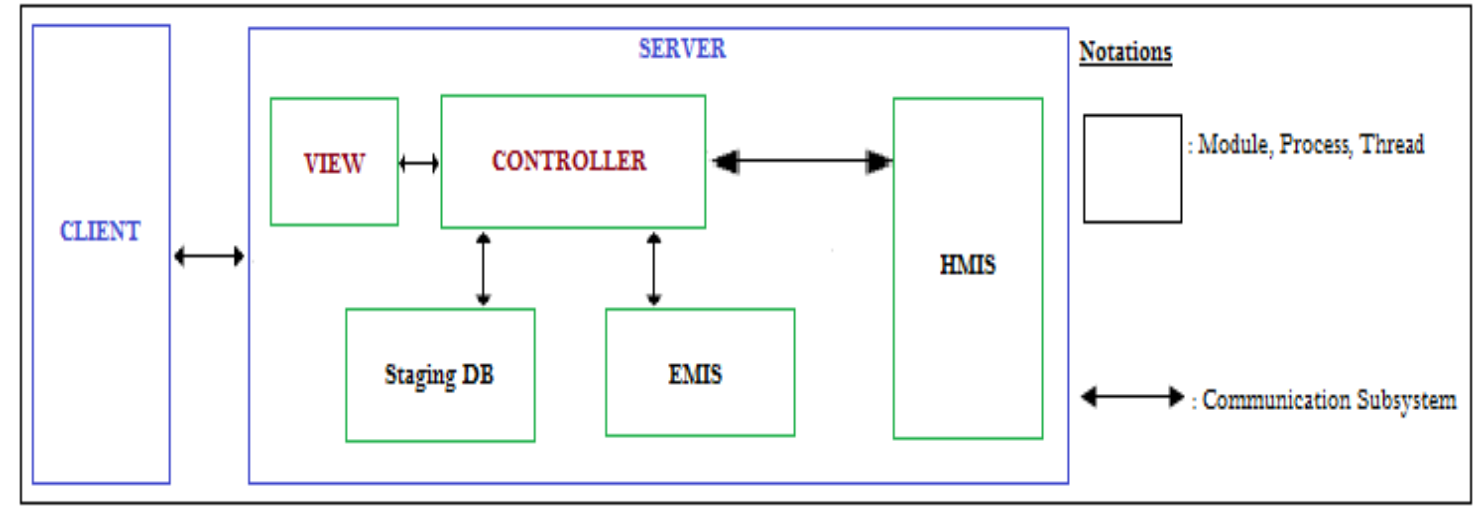

Figure 3 Design model of the proposed system

The model was further instantiated into a conceptual framework in order to provide a blueprint for development processes as shown in Figure 4. In brief, the conceptual framework consists of a mobile phone application which enables the patients to securely register to the system, and then submit data such as patient age, sex, geo-location are collected to the staging database (Staging DB). The system administrator at the hospital assists in the complete submission of environmental data including the climatology factors into the EMIS. Then, the communication subsystem integrates data from Staging DB and EMIS, and then sends them into the HMIS. At this stage, the data is ready to be sent to the registrar for further medical activities. Afterward, all the collected data and the laboratory results of the patients are sent to the epidemiological analysts for further analyses.

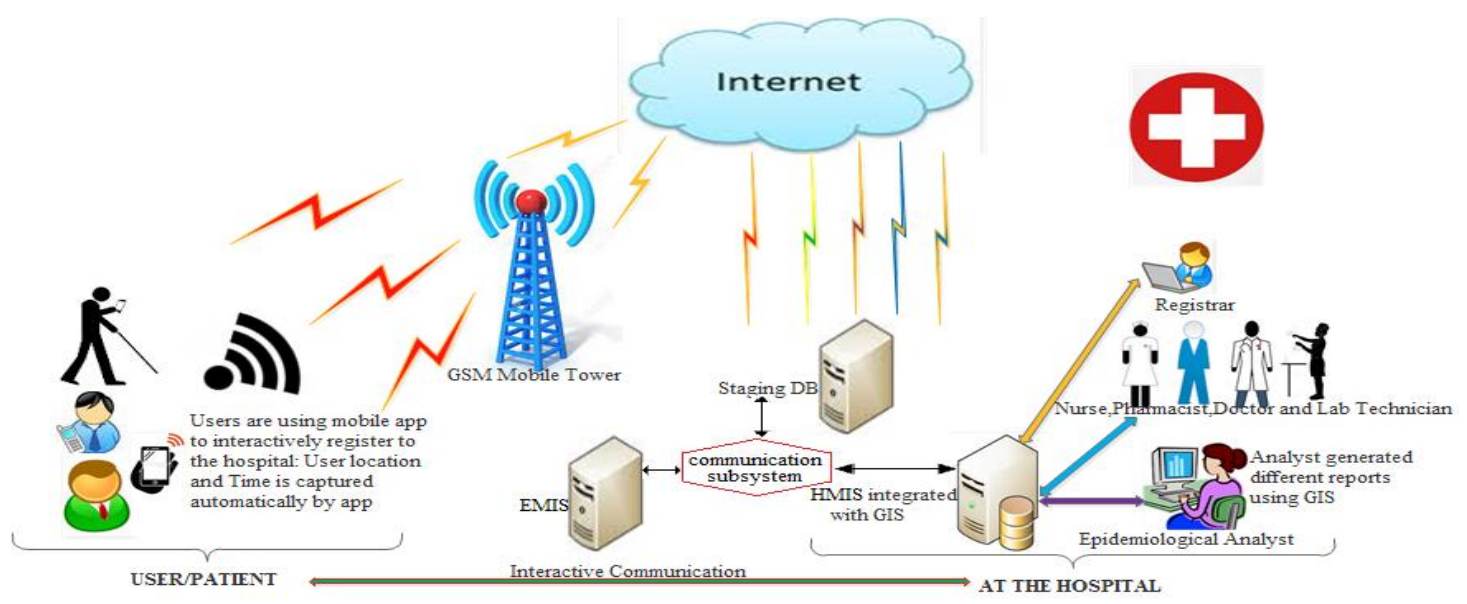

Figure 4 Conceptual framework of climatology-aware HMIS

\subsection{System description}

The developed system consists of (i) a mobile application which is responsible for data collection and sensing; along with data processing, e.g. feature extraction and automatic data upload to the Staging DB for storage (ii)an EMIS, which is responsible for the collection of environmental data such as climatology variables using sensors and satellite. The satellite and sensors work together to collect daily weather data and the load balancer crosschecks the collected data before their submission to the EMIS. (iii) a communication subsystem which integrates the data from Staging $\mathrm{Db}$ and EMIS and then submits 168 them to the web-based HMIS for further processing and (iv) a web-based HMIS which processes the integrated data with lab-results, the patient's historical data and doctor's comments, and then transforms the data into required visual formats such as Excel, graphs, and map-based reports. Figure 5 shows an overview of the development system.

The following are the main features of the developed system: data format interface, report sample of the system, and security interface, which are described in subsections: $3.3 .1,3.3 .2$, and 3.3 .3 respectively. 
The Staging, EMIS and HIS databases were developed rapidly and in parallel in order to allow users to input and access information during the testing phase. The interfaces for GIS and ML-based HMIS, satellite-based EMIS, and sensor-based EMIS were developed using Java Server Page (JSP), JavaScript and Java. Lastly, the android mobile-app was also developed using Java and connected to the MySQL database using JSON.

3.3.1The data format interface

Figure 6 shows the required data format which includes patients' details with their environmental factors such as climatology aspects.

\subsubsection{Report sample of the system}

Figure 7 presents a map-based report, which can be generated by the epidemiological analysts. The red, blue, purple, and green icons present cholera patients with respect to their home geographical location.

3.3.3The security interfaces

Figure 8 shows the mobile application access point interface where the security features for registering the patients are done. In addition, the mobile interface captures the patient's details such as; full name, age, sex, geographical location and date on set.

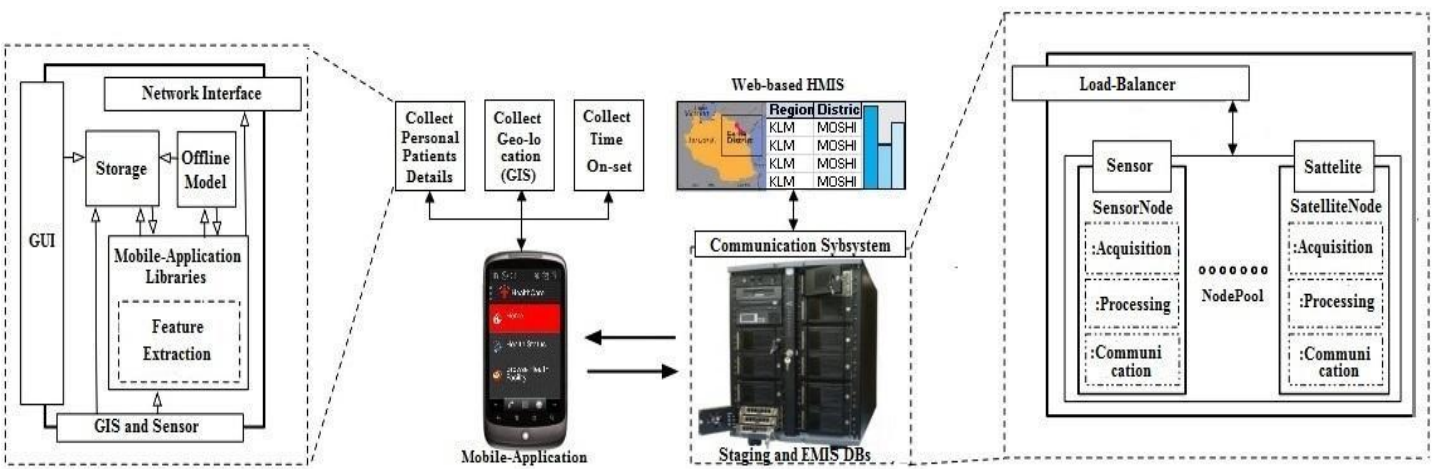

Figure 5 Description of the developed system
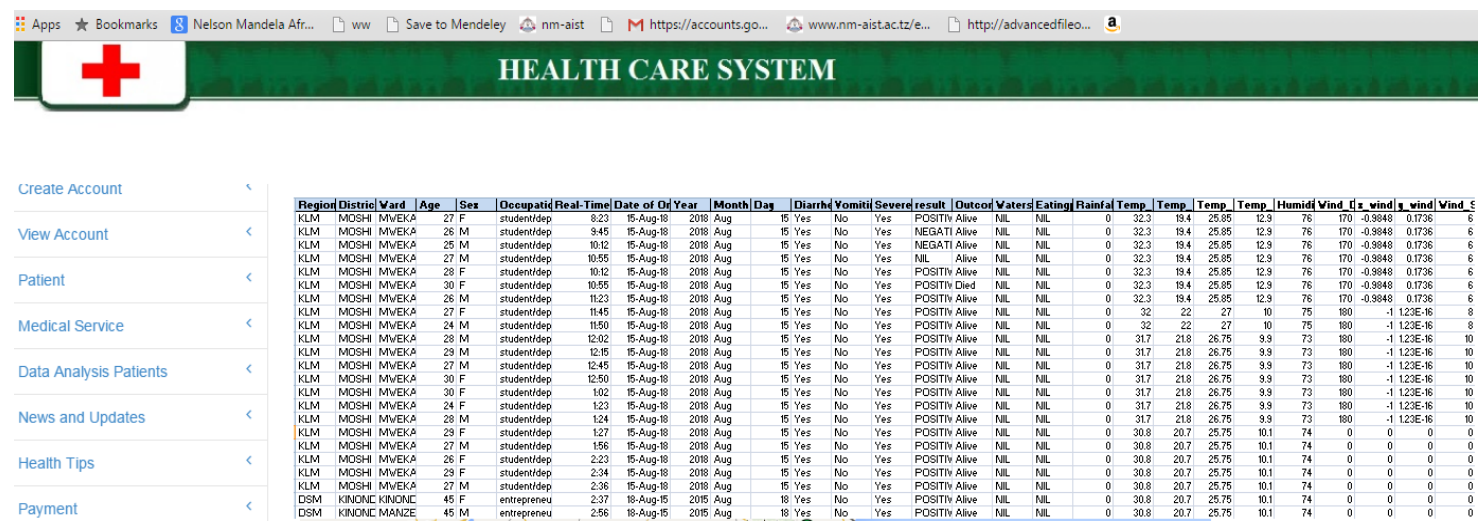

Figure 6 Data format interface of the developed system
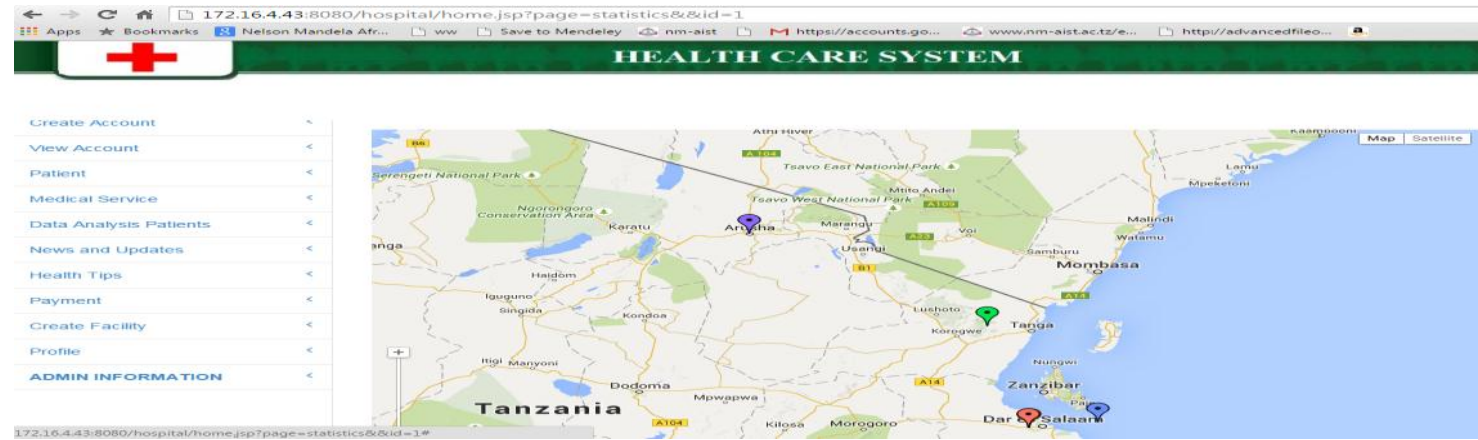

Figure 7 Map-based report of the developed system 
Judith Leo et al.

\subsection{Result of system evaluation}

This subsection presents the evaluation results on whether the developer system truly does make it easier to manage cholera epidemics.

3.4.1System requirements evaluation

Table 3 describes, in brief, the fulfillment of the functional requirements in the developed system.

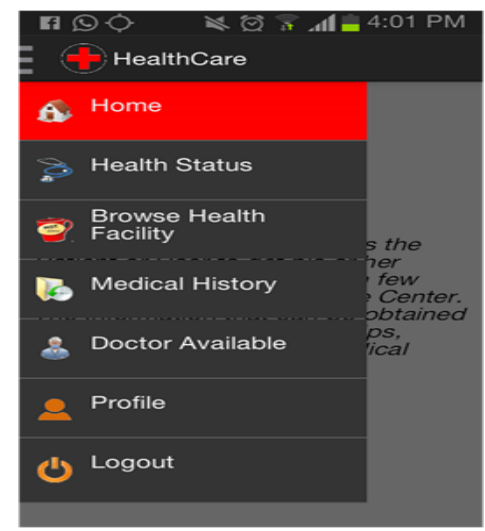

Figure 8 Security interface of the developed system

Table 3 System requirements verification featured in the questionnaires

Requirements
The developed system should collect
health and environmental data, including
the climatology variables, date and time
on set, patient's personal, and home
geographical location on-time.
The developed system must be able to
produce required data format and store
data acquired.
The developed system must be able to
manipulate the collected data and
establish the required data analysis report
format.
The developed system should secure data
effectively.

The developed system should secure data
effectively.

developed system must be simple and flexible.

\section{System verification}

The developed system has integrated advanced ICT to collect the required data for the analysis into one platform hence, timely data collection and analysis is inevitable.

The developed system consists of Staging DB, EMIS and communication subsystem to manage and control the required data format and storage.

The developed system has integrated advanced ICT such as mobile application, ML and GIS in the control module in order to analyze data on-time.

This is achieved through the adoption of client-server architecture style across all modules or parts of the developed system. The architecture style enables users to access the system as clients by sending requests to the server while the information control subsystem is associated with a back-end server to handle requests from clients. In addition, all patients have a unique password and identification for accessing the system (mobile or web application).

The developed system adopts MVC and RAD which iteratively breaks the task into small modules, then creates them independently and then join them together to represent a larger system. The modular design facilitates customization by allowing different parts of the system to be easily added, removed, and rearranged. Hence the developed system flexible, simple and can easily be customized to fit the needs of the users.

\subsubsection{System evaluation}

The overall results of the system evaluation in Figure 9 show that at an average of $87 \%$ users provided positive comments on the development system in terms of its efficiency, accessibility, security, maintainability, interoperability, collection of essential health and environmental data, and enhancement of cholera epidemic analysis. The remaining $13 \%$ of the average results represent participants who were not sure of the security and accessibility levels of the systems. Hence, we trained the participants, on how to secure their data and connect their Smartphone with reliable and affordable internet connections in Tanzania. In addition, the analytical result of the system showed that $88.5 \%$ of participants (households) had cholera disease as shown in Figure 10 and Table 4. 


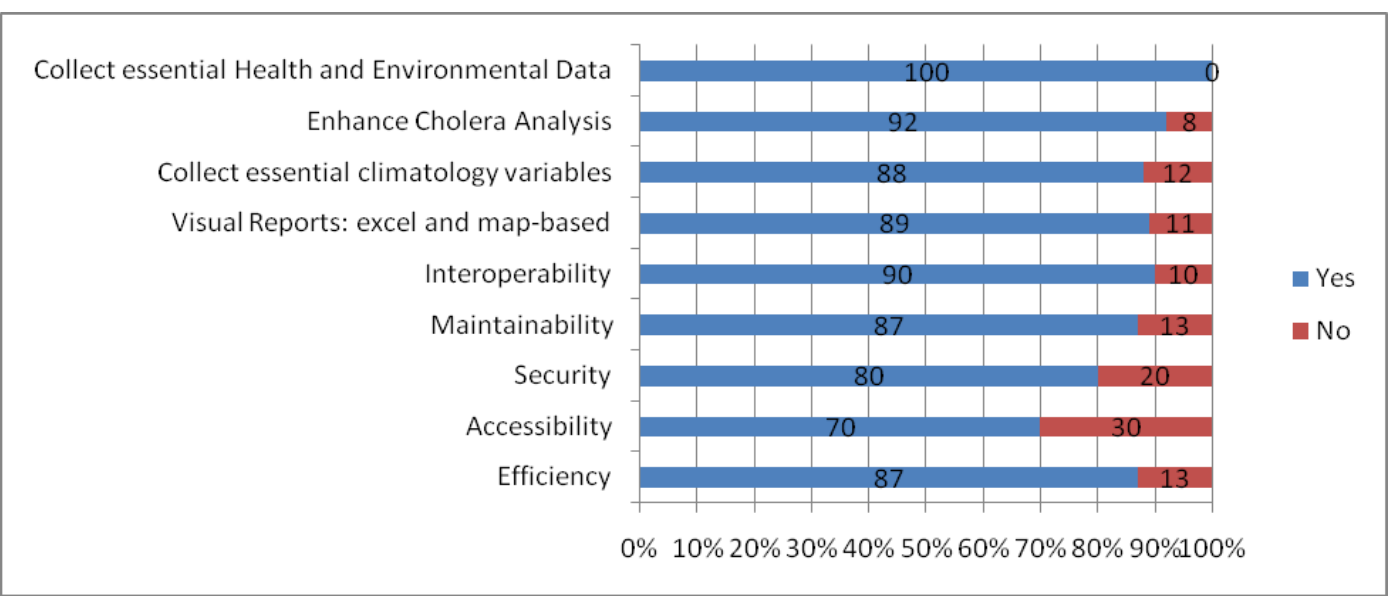

Figure 9 Results of system evaluation
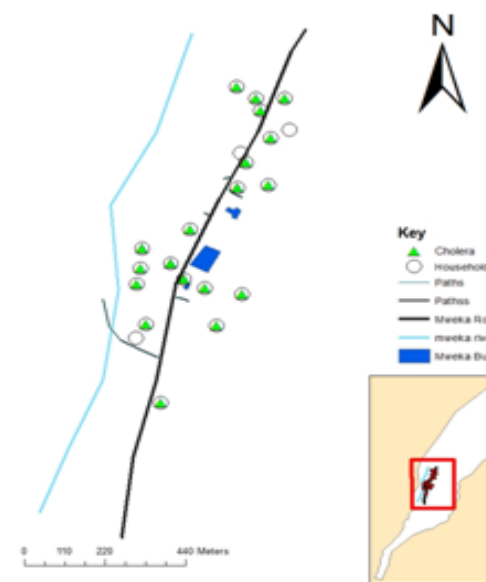

Table 4: Description of Cholera in Figure 10

\begin{tabular}{|l|l|}
\hline CHOLERA & n (\%) \\
\hline Yes & $21(88.5)$ \\
\hline No & $1(11.5)$ \\
\hline
\end{tabular}
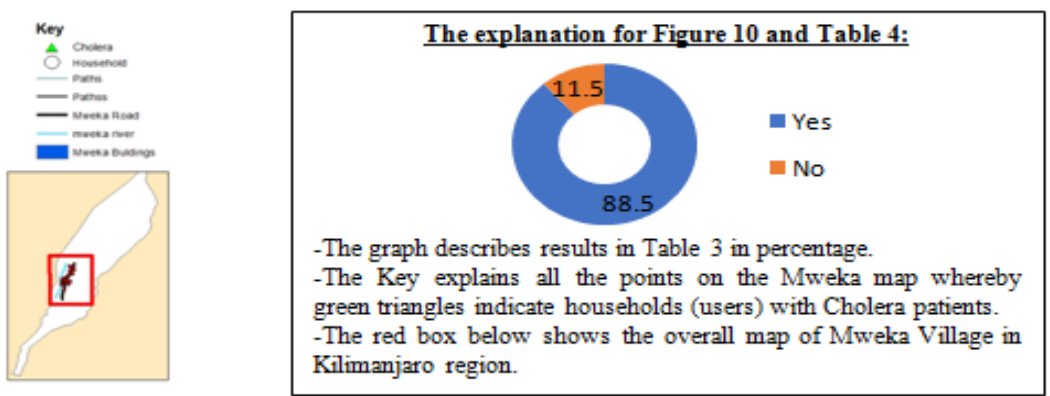

Figure 10 Cholera reported incidences in Mweka village

\section{Discussion}

The developed Climatology-aware HMIS has captured all required aspects of the environmental factors, particularly, the climate change into the HMIS. Hence, the system is better suited to enhance cholera epidemic analysis in the Tanzanian context compared to other systems such as HIMSs for the interoperability platform [31]. This is because; it has used ICTs which are affordable and easily accessible in Tanzania. It has also fulfilled the intended goal of enhancing timely cholera epidemics analysis since, all essential required data such as; geographical areas of patients' home and hospital, date and time on the set of the patient and daily climatology data are collected effectively in a single platform. The collected date and time variables assist in linking the epidemic events with its associated environmental variables such as the weather patterns. In addition, the system can display the collected data in different level of excel sheet which can be visualized in different formats such as; map-based report formats as shown in Figure 7 and Figure 10. Overall, the developed system leads to the intended goal of designing and developing appropriate HMIS capable of timely collection of environmental data. Hence, through the use of the developed system analyses of epidemic diseases such as cholera can be effective and timely achieved. However, the developed system cannot be used with basic phones and also, was evaluated on a small scale. We, therefore, recommend the extension of the study in the future to feature basic phones and also, to evaluate the developed system on a large scale.

\section{Conclusion}

The effects of environmental determinants, especially the climatology factors have been a growing concern in various epidemiological studies. Therefore, the recognition of climatology into HMIS is essential towards controlling the overall burden of diseases, 
particularly in the developing countries where the capacity to manage climate-sensitive diseases such as cholera epidemics constrains the prospects of achieving the Millennium Development Goals [6]. This work has shown clearly that the cholera epidemic is very common in Tanzania and also, the integration of climatology into HMIS enhances cholera epidemic analysis. In addition, the use of GIS, mobile application, satellite, and sensor technologies into the Climatology-aware HMIS proved to manage effectively the analysis and prediction of cholera epidemics. The study, therefore, recommends a review of systems and policies in the health sector in order to adapt climatology factors and effective use of advanced ICTs in order to boost healthcare data management which will enhance at large the development of health nations worldwide.

\section{Acknowledgment}

The authors wished to thank the study participants for their contribution to the research.

\section{Conflicts of interest}

The authors have no conflicts of interest to declare.

\section{Funding information}

This study has been sponsored by the African Development Bank (AfDB) and The Nelson Mandela African Institution of Science and Technology (NM-AIST).

\section{Ethical approval}

The study has been approved by the Nelson Mandela African Institution of Science and Technology Health Care Research Board in Tanzania.

\section{References}

[1] https://microbiologyonline.org/file/e507d924d199de0ad 42c1e59c7809547pdf. Accessed 26 April 2019.

[2] https://www.who.int/wer/2018/wer9338/en/. Accessed 26 April 2019.

[3] Pascual M, Bouma MJ, Dobson AP. Cholera and climate: revisiting the quantitative evidence. Microbes and Infection. 2002; 4(2):237-45.

[4] Grace JA. The alhema of the queiles river and the sisters of the huecha (History of an Arabism in the terminologies of Navarre and Aragonese irrigation). Prince of Viana. 1977; 38 (146): 163-8.

[5] Trærup SL, Ortiz RA, Markandya A. The costs of climate change: a study of cholera in Tanzania. International Journal of Environmental Research and Public Health. 2011; 8(12):4386-405.

[6] Trærup SL, Ortiz RA, Markandya A. The health impacts of climate change: a study of Cholera in Tanzania. BC3 Working Paper Series.2010.

[7] Smucker TA, Wisner B, Mascarenhas A, Munishi P, Wangui EE, Sinha G, et al. Differentiated livelihoods, local institutions, and the adaptation imperative: assessing climate change adaptation policy in Tanzania. Geoforum. 2015; 59:39-50.

[8] Kanungo S, Sah BK, Lopez AL, Sung JS, Paisley AM, Sur D, et al. Cholera in India: an analysis of reports, 1997-2006. Bulletin of the World Health Organization. 2010; 88:185-91.

[9] Rebaudet S, Sudre B, Faucher B, Piarroux R. Environmental determinants of cholera outbreaks in inland Africa: a systematic review of main transmission foci and propagation routes. The Journal of Infectious Diseases. 2013; 208(suppl_1):S46-54.

[10] El-Gayar O, Fritz BD. Environmental management information systems (EMIS) for sustainable development: a conceptual overview. Communications of the Association for Information Systems. 2006:75684.

[11] Codeço CT. Endemic and epidemic dynamics of cholera: the role of the aquatic reservoir. BMC Infectious Diseases. 2001.

[12] De Magny GC, Murtugudde R, Sapiano MR, Nizam A, Brown CW, Busalacchi AJ, et al. Environmental signatures associated with cholera epidemics. Proceedings of the National Academy of Sciences. 2008; 105(46):17676-81.

[13] Escobar LE, Ryan SJ, Stewart-Ibarra AM, Finkelstein JL, King CA, Qiao H, et al. A global map of suitability for coastal Vibrio cholerae under current and future climate conditions. Acta Tropica. 2015; 149:202-11.

[14] Mukhopadhyay AK. Mapping of cholera cases using satellite based recording systems to investigate the outbreak. The Indian Journal of Medical Research. 2015; 142(5):509-11.

[15] Rita R. Cholera and climate: a demonstrated relationship. Transactions of the American Clinical and Climatological Association. 2009; 120:119-28.

[16] Lugomela C, Moyo S, Lyimo TJ, Namkinga LA, Goericke R, Sjöling S. Co-variations of cholera with climatic and environmental parameters in coastal regions of Tanzania. Western Indian Ocean Journal of Marine Science. 2014; 13(1):93-105.

[17] Narra R, Maeda JM, Temba H, Mghamba J, Nyanga A, Greiner AL, et al. Notes from the field: ongoing cholera epidemic-Tanzania, 2015-2016. MMWR. Morbidity and Mortality Weekly Report. 2017; 66(6):177-8.

[18] Antwi-Agyei P, Mwakitalima A, Seleman A, Tenu F, Kuiwite T, Kiberiti S, et al. Water, sanitation and hygiene (WASH) in schools: results from a process evaluation of the national sanitation campaign in Tanzania. Journal of Water, Sanitation and Hygiene for Development. 2017; 7(1):140-50.

[19] Conrad PA, Mazet JA, Clifford D, Scott C, Wilkes M. Evolution of a transdisciplinary "One Medicine-One Health" approach to global health education at the university of California, Davis. Preventive Veterinary Medicine. 2009; 92(4):268-74.

[20] Darcy N, Elias M, Swai A, Danford H, Rulagirwa H, Perera S. eHealth strategy development: a case study in Tanzania. Journal of Health Informatics in Africa. 2014; 2(2). 
[21] Seleman A, Bhat MG. Multi-criteria assessment of sanitation technologies in rural Tanzania: implications for program implementation, health and socio-economic improvements. Technology in Society. 2016; 46:70-9.

[22] Boisson S, Engels D, Gordon BA, Medlicott KO, Neira MP, Montresor A, et al. Water, sanitation and hygiene for accelerating and sustaining progress on neglected tropical diseases: a new global strategy 2015-20. International Health. 2016; 8(suppl_1):i19-21.

[23] Molyneux DH, Savioli L, Engels D. Neglected tropical diseases: progress towards addressing the chronic pandemic. The Lancet. 2017; 389(10066):312-25.

[24] Fitzpatrick C, Engels D. Leaving no one behind: a neglected tropical disease indicator and tracers for the sustainable development goals. International Health. 2016; 8(suppl_1):i15-8.

[25] Mshana SE, Matee M, Rweyemamu M. Antimicrobial resistance in human and animal pathogens in Zambia, democratic republic of Congo, Mozambique and Tanzania: an urgent need of a sustainable surveillance system. Annals of Clinical Microbiology and Antimicrobials. 2013; 12(28).

[26] World Health Organization. Health security and emergencies cluster outbreaks and emergencies bulletin. Bulletin Outbreaks and Emergencies. 2016; 6(2).

[27] Walldorf JA, Date KA, Sreenivasan N, Harris JB, Hyde TB. Lessons learned from emergency response vaccination efforts for cholera, typhoid, yellow fever, and Ebola. Emerging Infectious Diseases. 2017; 23(13).

[28] Mghamba JM, Mboera LE, Krekamoo W, Senkoro KP, Rumisha SF, Shayo E, Mmbuji P. Challenges of implementing an integrated disease surveillance and response strategy using the current health management information system in Tanzania. Tanzania Journal of Health Research. 2004; 6(2):57-63.

[29] Kiwanuka A, Kimaro HC, Senyoni W. Analysis of the acceptance process of district health information systems (DHIS) for vertical health programmes: a case study of TB, HIV/aids and malaria programmes in Tanzania. The Electronic Journal of Information Systems in Developing Countries. 2015; 70(1):1-14.

[30] Morrison C, Iosif A, Danka M. Report on existing opensource electronic medical records. University of Cambridge, Computer Laboratory; 2010.

[31] Kajirunga A, Kalegele K. Analysis of activities and operations in the current E-Health landscape in Tanzania: focus on interoperability and collaboration. arXiv Preprint arXiv:1507.00176. 2015.

[32] Mugerezi E, Salaam DE, Sustainable T. An environmental management information system (EMIS) for iringa municipality, Tanzania implementation challenges. International Archives of the Photogrammetry, Remote Sensing and Spatial Information Sciences. 2000; 34(Part 6):78-86.

[33] Smith M, Madon S, Anifalaje A, Lazarro-Malecela M, Michael E. Integrated health information systems in Tanzania: experience and challenges. The Electronic Journal of Information Systems in Developing Countries. 2008; 33(1):1-21.
[34] Gawanmeh A, Al-Hamadi H, Al-Qutayri M, Chin SK, Saleem K. Reliability analysis of healthcare information systems: State of the art and future directions. In international conference on e-health networking, application \& services (HealthCom) 2015 (pp. 68-74). IEEE.

[35] Sonke J, Rollins J, Brandman R, Graham-Pole J. The state of the arts in healthcare in the United States. Arts \& Health. 2009; 1(2):107-35.

[36] Curran KG, Wells E, Crowe SJ, Narra R, Oremo J, Boru W, et al. Systems, supplies, and staff: a mixed-methods study of health care workers' experiences and health facility preparedness during a large national cholera outbreak, Kenya 2015. BMC Public Health. 2018; 18(1):723.

[37] Smith M, Madon S, Anifalaje A, Lazarro-Malecela M, Michael E. Integrated health information systems in Tanzania: experience and challenges. The Electronic Journal of Information Systems in Developing Countries. 2008; 33(1):1-21.

[38] Karimuribo ED, Mboera LE, Mbugi E, Simba A, Kivaria FM, Mmbuji P, et al. Are we prepared for emerging and re-emerging diseases? Experience and lessons from epidemics occurred in Tanzania during the last five decades. Tanzania Journal of Health Research. $2011 ; 13(5): 1-14$.

[39] Igira FT, Titlestad OH, Lungo JH, Makungu A, Khamis MM, Sheikh Y, et al. Designing and implementing hospital management information systems in developing countries: case studies from Tanzania-Zanzibar. Health Informatics in Africa (HELINA). 2007.

[40] Kwesigabo G, Mwangu MA, Kakoko DC, Warriner I, Mkony CA, Killewo J, et al. Tanzania's health system and workforce crisis. Journal of Public Health Policy. 2012; 33(1):S35-44.

[41] Simba DO, Mwangu M. Application of ICT in strengthening health information systems in developing countries in the wake of globalisation. African Health Sciences. 2004; 4(3):194-8.

[42] Naves LA, Porto LB, Rosa JW, Casulari LA, Rosa JW. Geographical information system (GIS) as a new tool to evaluate epidemiology based on spatial analysis and clinical outcomes in acromegaly. Pituitary. 2015; 18(1):8-15.

[43] Nykiforuk CI, Flaman LM. Geographic information systems (GIS) for health promotion and public health: a review. Health Promotion Practice. 2011; 12(1):63-73.

[44] de la Torre I, Benito-Calvo A. Application of GIS methods to retrieve orientation patterns from imagery; a case study from Beds I and II, Olduvai Gorge (Tanzania). Journal of Archaeological Science. 2013; 40(5):2446-57.

[45] Pascoe L, Lungo J, Kaasbøll J, Koleleni I. Collecting integrated disease surveillance and response data through mobile phones. In proceedings of the ISTAfrica conference and exhibition 2012 (pp. 9-11).

[46] Nasi G, Cucciniello M, Guerrazzi C. The role of mobile technologies in health care processes: the case of cancer supportive care. Journal of Medical Internet Research. 2015; 17(2):e26. 
[47] Aker JC, Mbiti IM. Mobile phones and economic development in Africa. Journal of Economic Perspectives. 2010; 24(3):207-32.

[48] https://www.gsma.com/publicpolicy/wpcontent/uploads/2012/03/SSA_FullReport_v6.1_clean.p df. Accessed 26 April 2019.

[49] Geerts GL. A design science research methodology and its application to accounting information systems research. International Journal of Accounting Information Systems. 2011; 12(2):142-51.

[50] Lank E, Withee K, Schile L, Parker T. User centred rapid application development. In International Workshop on Rapid Integration of Software Engineering Techniques 2005 (pp. 34-49). Springer, Berlin, Heidelberg.

[51] Arkkelin D. Using SPSS to understand research and data analysis.2014.

[52] Leff A, Rayfield JT. Web-application development using the model/view/controller design pattern. In proceedings of the international enterprise distributed object computing conference 2001 (pp. 118-27). IEEE.

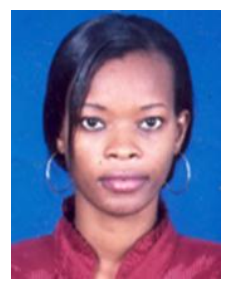

Judith Leo, is a Ph.D. students at the Nelson Mandela African Institution of Science and Technology, Arusha Tanzania. I was born on the 23rd of January 1983. I did bachelor in Electronics and Communication Engineering in Bangalore-India, Master's in Information and Communication Science and Engineering at NM-AIST and currently, am pursuing Ph.D. degree in Information and Communication Science and Engineering specializing in Information Technology System Development and Management.

Email: judithleoherman@gmail.com

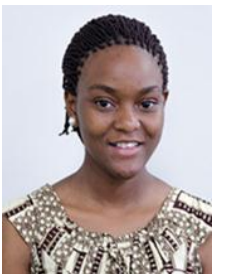

Edith Luhanga received her Ph.D. in Information Science (focusing on ubiquitous computing applications) from the Nara Institute of Science and Technology in 2018. She also holds an MSc in Advanced Computing Science and a BEng (Hons) in Electronic and Computer Engineering from the University of Nottingham. She is a lecturer at the Nelson Mandela African Institution of Science and Technology (NM-AIST) in Arusha, Tanzania. Her research interests include Developing Mobile and its Applications, humancomputer interactions and Applied Artificial Intelligence.

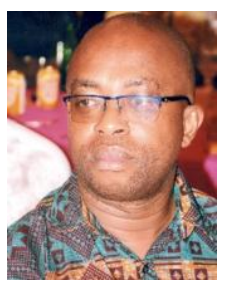

Kisangiri Michael was born in 1973, DarEss Salaam Tanzania. He started his education journey in 1980. In 1993 he finishes, advanced level secondary at Tambaza secondary school in Dar-EsSalam Tanzania. In 1995 he started university education in Poland; first, he joins Language school in Lodz, then joins Wroclaw University of Science and Technology for Master degree program in Telecommunication major in mobile telecom from 1996 to 2001, then Ph.D. in Telecommunication in the same university from 2004 to 2008. Dr Kisangiri Francis Michael has been working with Nelson Mandela African Institution of Science and Technology (NM-AIST) as a lecturer then Senior lecturer since December 2011. Before joining NM-AIST he worked with Dar-Es-Salaam Institute of Technology DIT. He has successfully managed dozens of researches in the level of MSc degree and several of the level Ph.D. degree. He possesses good knowledge in Artificial intelligence, Antenna design, and wireless communication systems. His research interest is in Machine learning, Internet of Things (IoT), eHealth and MIMO antenna. 